\title{
Prevalence of soil-transmitted helminthiases among pre-school age children (12-59 months) and WASH condition in Mkuranga, Tanzania: a cross-sectional study
}

UMMUL-KHAIR MUSTAFA ( $\square$ ummybadia@gmail.com )

DAR ES SALAAM UNIVERSITY COLLEGE OF EDUCATION https://orcid.org/0000-0002-1620-8952

Donath Samuel Tarimo

Muhimbili University of Health and Allied Sciences

\section{Research Article}

Keywords: Preschool aged children, preventive chemotherapy, water, sanitation, hygiene, STH, Mkuranga,

Tanzania

Posted Date: July 13th, 2020

DOI: https://doi.org/10.21203/rs.3.rs-40970/v1

License: (c) (i) This work is licensed under a Creative Commons Attribution 4.0 International License.

Read Full License 


\section{Abstract \\ Background}

National efforts for STH control have hitherto been concentrated on school age children (SAC) excluding pre-school age children (PSAC). Though Preventive Chemotherapy (PC) for PSAC has been going on during deworming and vitamin A supplementation campaigns in the Reproductive and Child Health (RCH) clinics since 2004, it has not been optimal because not all PSAC receive PC thus remaining vulnerable to STH infections and potential source of community transmission. This study examined the prevalence and intensity of STHs infections among PSAC and the associated water, sanitation and hygiene (WASH) factors in Mkuranga district, Tanzania.

\section{Methods}

A quantitative community based cross-sectional study was conducted between April and June 2019 . Stool samples from 525 PSAC were examined for STH infections. This was complemented with a questionnaire interview of mothers/caretakers of the PSAC to obtain their socio-demographic characteristics and WASH practices. An observation check list was used to gather environmental WASH practices. Data were analyzed by statistical computer package (SPSS version 23), and summarized by descriptive statistics; proportions were compared by the Chi-square test at the significance level of 0.05 .

\section{Results}

The overall prevalence of STH infection was very low (1.3\%) and was significantly associated with condition of child finger nails $(P=0.001)$ and place of disposal of faecal matter $(P=0.031)$. Latrine coverage was very high (97.3\%), while disposal of children faeces was $100 \%$ hygienic. Less than a half $(43.6 \%)$ of households were using improved latrines. Majority (95\%) of households had access to improved water sources; however, only few (5.3\%) treated drinking water. Very few (1.3\%) households owned hand washing facilities, conceivably leading to a low practice of hand washing with soap at food preparation (12.8\%), child feeding (13\%), after defecation (34.1\%) and after handling children faeces $(23 \%)$. Nail trimming habit was very good as a large majority (83.8\%) of caretakers and corresponding children $(87.2 \%)$ had their finger nails trimmed at time of survey.

\section{Conclusion}

PSAC are a reservoir of STHs infections, which coupled with the prevalent risk factors of transmission, form a potential source of continuity of transmission in the community, hence the need for a national deworming program extending to PSAC 


\section{Background}

Soil-transmitted helminthiases (STH) is a term referring to a group of parasitic nematodes of the intestinal tract transmitted to humans by faecally contaminated soil (1). STH of major public health importance include Ascaris lumbricoides (round worms), Trichuris trichiura (whipworms), Necator americanus and Ancylostoma duodenale (hookworms) (1). They affect more than 1.5 billion people worldwide and the most affected are Preschool Age Children (PSAC) and School Age Children (SAC) in Sub-Saharan Africa (2). Humans are infected by ingesting infective eggs (Ascaris lumbricoides and Trichuris trichiura) orlarvae (Ancylostoma duodenale) or skin penetration by infective larvae of hookworms (Necator americanus and Ancylostoma duodenale) in the soil $(3,4)$. Heavy infections delays physical and cognitive development and interferes the body ability to respond to disease vaccines $(5,6)$. Preventive chemotherapy (PC) to SAC using Albendazole or Mebendazole at coverage of $75 \%$ and above is a strategy recommended by World Health Organization (WHO) for controlling STH in children (3). This is complemented by the provision of adequate water, sanitation, hygiene services and health education as fundamental for breaking the cycle of infection and reinfections (7).

In Tanzania more than $65 \%$ of the children (both PSAC and SAC) harbour STH infections (8), however, national efforts for control have hitherto been concentrated on SAC (9) excluding the PSAC who are among persons at risk of infection. Though PC for PSAC using Mebendazole have been going on during vitamin A and deworming campaign and routine child growth monitoring in the $\mathrm{RCH}$ clinics since 2004 $(10,11)$, this strategy has not been optimal because such visits are rare for older children $>12$ months (12-14) implying that a portion of PSAC do not actually receive treatment and remain at risk of STH infections. According to national reports the proportion of PSAC that received PC in the year 2014, 2015 and 2018 were only $70 \%, 38 \%$ and $50 \%$ respectively $(11,15,16)$. PSAC have been shown to be at an increased risk to STH with a surprisingly high levels of infection by Ascariasis $(32.1 \%)$ and Trichuriasis (38.4\%) (17), thus becoming a potential source of transmission in the community. The burden of STH among PSAC residing in areas with favorable ecological conditions for STHs transmission has not been established. This study examined the burden of STHs infections among PSAC and the associated water, sanitation and hygiene (WASH) factors in Mkuranga district, Tanzania; to gather data that will contribute to policy decisions regarding STH control in the country.

\section{Methods}

\section{Study area}

The study was carried out in Mkuranga district, Pwani region; the district boarders with Dar es Salaam region, Indian Ocean, Rufiji district, and Kisarawe district to the north, east, south and west respectively (Figure 1). The district is divided into 4 divisions, 18 wards and 121 villages and 463 hamlets. According to population and housing census of 2012 the district has a total population of 222,921 of which males were 108,024 and females were 114,897 (18). It has a total of 50 health facilities (public and private) which offer health services including RCH clinics. The district has favorable ecological condition for STH; 
it is one of the worst districts in Tanzania in terms of access to piped or protected water sources. As for $2002,93 \%$ and $76 \%$ of rural and urban household respectively were using unprotected water source for drinking (19). The most common toilet facility (2002) is the traditional pit latrine owned by 89 per cent of house hold and $10.82 \%(2007 / 08)$ had no toilet (19)

\section{Figure 1: Map of Tanzania showing the location of Mkuranga district (20).}

\section{Study design, sample size and enrollment of participants}

A quantitative community based cross-sectional study was conducted between April and June 2019 to examine the prevalence and intensity of STHs among PSAC and the associated WASH factors. Two study populations were recruited: 525 PSAC for establishing the prevalence and intensity of STHs and 525 parents/caregivers for interview on their socio-demographic characteristics and WASH practices.

The sample size, 525 PSAC was determined using the formula for single population proportion (21) and considering $30 \%$ Prevalence of STH in the population (22), normal deviate of $1.96,95 \%$ Confidence interval, $5 \%$ Margin of error, $10 \%$ non-response rate and design effect of 1.5 .

Sampling was done in four stage clusters:

In the first stage two wards of Vikindu and Mwalusambe were randomly selected from eighteen wards using lottery system.

At the second stage, using lottery methods, two villages namely Kazole and Mwalusambe were randomly selected from Vikindu and Mwalusambe respectively.

In the third stage, the hamlets of Kilongoni and Mwalusambe Mjini were randomly selected from Kazole and Mwalusembe village respectively.

In the fourth stage, 525 PSAC and their corresponding mothers/caretakers were selected from each hamlet. Allocation of sample sizes was done by proportionate sampling based on the number of household found in each hamlet. We obtained the number of household in each hamlet from the hamlet chairman and the contribution of household to sample size was calculated by using the formula of probability proportional to size (Equation 1). Kilongoni hamlet had a total of 429 households while Mwalusembe Mjini hamlet had a total of 401 households.

Using the formula of probability proportion to sampling: number of house hold per hamlet $=$

Total households from the hamlet x Sample size required for the study_(1) Grand total number of households in the two hamlets

Thus, a total of 271 and 254 household were selected to represent Kilongoni and Mwalusambe Mjini hamlets respectively 
To obtain households, the office of the hamlet chairman was used as a central location and starting point. A bottle was spun to determine direction; the household closest to the office in the direction of the bottle was selected as the initial household. The next nearest household was selected until the estimated sample was obtained. Whenever more than one eligible child was found in the same household, one of them was chosen using a lottery method.

\section{Inclusion and exclusion criteria}

PSAC (12-59 months) living in the study area in the past six month and whose parents or legal guardians provided written consent were eligible to participate. Excluded were those who received anti-helminthic drug in the preceding one month, having diarrhea and those whose parents / care givers refused to sign a written consent.

\section{Data collection}

Stool samples collection, processing and examination

To establish prevalence and intensity of STH, stool samples were collected, processed and examined for presence of STH eggs. Number of eggs found in sample was used to establish intensity of infection. Children were allowed to defecate on a piece of paper; using an applicator a portion of the feacal matter was transferred to a pre-labeled clean, dry and wide mouthed stool container. Samples were preserved in $10 \%$ formalin and transferred to the MUHAS Parasitology laboratory for further processing and examination. Presence of parasites was established by direct wet mount iodine preparations and formolether concentration techniques, while parasite intensity was established by the Kato-Katz technique as described by WHO (23).

Prevalence of STH was calculated as the ratio of number of children found positive for any STH species to the total number of children who provided complete data (Equation 2).

Prevalence $=\underline{\text { Number of subjects testing }} \underline{\text { positive }} \times 100$ (2)

Number of subjects investigated

To determine the intensity, number of eggs of each species were recorded and converted into the number of eggs per gram of feces (EPG). EPG was calculated by multiplying egg count by conversion factor (24). Intensities were categorized (light/moderate/heavy infection) based on WHO categories (24). To ensure validity and reliability, standard operating procedures were followed during stool collection, processing, examination and analysis as described in the WHO bench mark aid for diagnosis of parasitic infections.

Socio-demographic characteristics and WASH practices:

Data were obtained through questionnaire interview with mothers/caretakers of PSAC. An observation check list was used to gather environmental WASH practices. For sanitation, we asked caretakers to show the households latrine facilities and then we categories them into improved non shared latrine vs. other 
types of latrines based on WHO, UNICEF definitions (25). On child sanitation, mothers/caretakers were asked on what they do when the child want to defacate and what is done to dispose the child faeces. We performed on spot observation to check for signs of open defecation around the house compound, outside latrine, on the latrine wall and around drop hole. Disposal of child faeces was categorized into hygienic/safe vs. unhygienic/not safe based on WHO, UNICEF definition (25).

To obtain data on drinking water, we asked respondents to mention the main source of drinking water. To determine quality of water sources, water sources were categorized into improved vs. unimproved according to WHO, UNICEF definition (25). We also investigated the habit regarding treatment of drinking water by asking the respondents to explain procedures taken to prepare drinking water at the household. Concerning hand hygiene, respondent were asked to explain their hand washing habit at critical times such as before preparing food, before feeding a child, after defecation and after cleaning a defecated child. We also investigated the presence of hand washing facilities. We investigated finger nails hygiene by observing mother/caretaker and the child finger nails and recorded them trimmed or untrimmed if the finger nails were cut short or kept long respectively.

\section{Statistical analyses}

Data were cleaned, coded and entered into Statistical Package for Social Sciences (SPSS) version 23. The data were summarized using frequency and proportion. Chi-square tests (Pearson chi square test and Fishers exact test) whenever applicable were performed to determine association between STH prevalence and WASH variables. A P value $<0.05$ was considered significant.

\section{Ethical considerations}

Ethical clearance was obtained from the MUHAS Ethical Review Board. Permission was obtained at all administrative units involved in this study. A written consent was obtained from parent or legal guardian of each participant. Any information obtained during the study was kept confidential. At the end of the study, a brief report was prepared and sent to the District health officers so that infected children would receive treatment.

\section{Results}

\section{Socio - demographic characteristics of the Pre-school age children and caretakers}

A total of 525 PSAC and their accompanying mothers / caretakers participated in the study. The mean age of PSAC was 36.71 (SD=14.3450) months, more than half $(52.4 \%)$ being females. The mean age of the mothers / caretakers was 30.78 years $(S D=9.143)$, about two thirds $(63.2 \%)$ had attained primary school education level; the large majority were biological parents (89.7\%) and married or cohabiting (81\%) (Table1). 


\section{Prevalence and intensity of STHs infections among PSAC}

A total of 525 stool samples were analysed, 7 were infected with at least one species of STH giving an overall prevalence of $1.3 \%$. Of the three types of STH, only two were recovered namely Ascaris lumbricoides (two samples) and hookworms (five samples). The arithmetic means intensity for Ascaris lumbricoides and hookworms ware $3.0 \mathrm{epg}$ and $6.9 \mathrm{epg}$ respectively. The mean eggs intensities for both species fall under light infections: A. lumbricoides (625 to $959 \mathrm{epg}$ ) and hookworms (375 to $1501 \mathrm{epg}$ ).

\section{Households drinking water characteristics}

The main source of water used for drinking was piped water located somewhere else/not in the dwelling or own yard or plot (42.7\%) followed by tube wells or bore holes (39.4\%). Other types of water sources used by households for drinking purpose were piped water located into dwellings/yard (7.8\%), protected wells $(5.1 \%)$, unprotected wells $(4.6 \%)$ and protected springs $(0.4 \%)$. When categorized into improved and unimproved water sources, it was found that the large majorities $(95.0 \%)$ of the respondents were using improved water sources and the remaining (5.0\%) were using unimproved water sources. However, only a small percentage $(5.3 \%)$ of the households treated drinking water. Boiling was the main method used to treat drinking water (92.6\%). Figure 2 show different water sources available in the study areas.

\section{Household's sanitation characteristics}

The large majority (97.3\%) of the households possessed a latrine, of which, less than a half (43.6\%) had improved non shared latrines; the rest (56.4\%) used other types of latrine. Most of the latrines were in poor conditions either due to absence of lockable door, absence of roof, and walls that maintain users' privacy, and absence of washable floor. Figure 3 show conditions of some of latrine found in the study areas.

On child sanitation, it was found that less than a half (46.7\%) defecated in a latrine, and the remaining defecated on the ground, on nappies or in potties. Mothers / caretakers whose children defecated either on the ground, on nappies or potties reported to dispose the faecal matters hygienically, the majority $(92.9 \%)$ disposing the faeces in a latrine, the remaining (7.1\%) burry them in the ground (Figure 4).

\section{Figure 4: methods used by caretakers to dispose children faeces.}

\section{Mothers / caretakers and child hand hygiene}

More than three quarters $(79.0 \%)$ of the mothers / caretakers reported washing their hands with water alone at all critical moments: before preparing food (79.0\%), before eating and feeding a child $(87.0 \%)$, after defecation (65.9\%) and after cleansing a child who had defecated $(77.0 \%)$. Use of soap with water (Table 2), was low and was used only after defecation (34.1) and after cleansing a child who has defecated $(23.0 \%)$. Only a small percentage $(1.3 \%)$ of the households had hand a washing place, the large majority (98.7\%) did not. The only type of hand washing place observed in the households were 
sinks. Of the 7 households with hand wash places, only 2 had water and soap while the remaining 5 had water only.

On finger nails hygiene, majority (83.8\%) of mothers / caretakers kept their finger nails trimmed at the time of the survey. Similarly, a large majority $(87.2 \%)$ of the children had their finger nails trimmed at the time of survey (Table 2).

\section{Influence of water and sanitation and hygiene practices on STH}

It was found that, children with untrimmed finger nails were significantly more likely to be infected with STH $(p=0.001)$ than those with trimmed finger nails (Table 3). Likewise children defecating on latrine had high likelihood of being infected $(p=0.031)$ than those defecating on potties, on the ground and on nappies.

\section{Discussion}

The prevalence of STH was (1.3\%) which is very low prevalence according to WHO classification $(3,24$, 26). This prevalence is lower than that reported in the neighboring district of Bagamoyo (3.8\%) (27). Low prevalence of STH among PSAC can be attributed to existence of deworming programme for PSAC and the sustained national school-based deworming conducted in SAC. Successful deworming of SAC can reduce the total burden of intestinal worms to the whole community $(25,28)$ The low prevalence of STH reported in this study should not be ignored, it denote continuity of STH transmission in Mkuranga and call for further efforts to increase coverage of deworming in PSAC because children left untreated are potential source of infection and reinfection in the community.

All cases of STH infection were of low intensities, similar to findings of study conducted in Gurage zone, Ethiopia (21). Low intensity infections is expected in areas with less than $20 \%$ prevalence of STH (3).

Drinking water from unimproved sources are associated with increased odds of infection of orallyingested species such as Ascaris lumbricoides, and Trichuris trichiura (29). In this study the proportion of households using improved water sources was very high (95\%). This figure is higher than that reported by Twaweza and Tanzania demographic survey (TDHS), (54\%) and (61\%) respectively $(15,30)$. A few years ago Mkuranga was known to be worse in terms of access to improved water sources (19), thus our study highlight progress in the access to improved water sources reached by the district. These achievements have been facilitated by private and faith based organizations involvement in water supplies: mainly through wells and boreholes accessed by community members as a paid service and or free of charge.

Water treatment by boiling, adding chlorine/bleaching, solar disinfecting and use of water filter is recommended to improve the quality of drinking-water (25). In our study majority of respondent $(94.7 \%)$ reported they do not treat drinking water. The figure is higher than that reported by national representative 
survey, Twaweza (60\%) (30) and TDHS (38\%) (15). Poor water treatment habit can be due to poverty; some people would not afford to boil water or perform other treatment methods due to high cost of boiling energy (charcoal, gas and electricity).

Faeces that are not hygienically disposed are potential source of transmission of STH, thus hygienic disposal of human faeces in improved latrines is highly recommended $(25,31,32)$. We investigated the availability and quality of latrines found in the study areas and methods used to dispose children faeces. The availability of latrine was very high (97.3\%), consistent with the reported coverage of $98.3 \%$ in Bagamoyo district within Pwani region (27). Our findings also agrees with those reported in National Sanitation Campaigns where latrine coverage was $94.7 \%$ (33) and re-affirm that latrine coverage in Tanzania is high. It was shown that less than a half (43.6\%) of households was using improved non shared latrines. Generally, use of improved non shared latrine is low at the national level 19\% (15). Concrete measures should be taken to create community awareness on the importance of using improved sanitation facilities.

In this study sanitary disposal of child faeces was $100 \%, 46.7 \%$ of caretakers reported that the child defacate in latrine, and the remaining defecated somewhere else followed by hygienic disposal of the faeces either by throwing into latrine or burring in the soil (25). This figure is higher than the national average where proportion of safe disposal of child faeces was $72 \%$ (15). Our findings disagree with the results from rural Bangladesh which reported $80 \%$ unsafe disposal of children faeces (34). Safe disposal of children faeces in our study is due to availability of pit and flush latrine which allow caretakers to throw or rinse faeces easily. Proper disposal of child faeces can also be attributed to the nature of the settlements where by houses were built close to each other and there was no man's land to throw faeces into.

Washing hands with soap before eating, before preparing food, after defecating and after cleaning a child who has defecated is emphasized to reduce STH transmission $(7,35)$. The hand washing habit of mothers/caretakers was poor, as only few $12.8 \%$ reported using soap during hand wash before preparing food, and $13.0 \%$ before feeding a child, $34.1 \%$ after defecation and $23.0 \%$ after cleaning a defecated child. Our findings agrees those of the national baseline survey which showed that only $21.2 \%, 12.5 \%$, $9.7 \%$ and $9.1 \%$ were using soap during hand wash after using toilet, before cooking or preparing foods, before feeding children and after cleaning children bottom respectively (36). Poor hand washing habit can be due to lack of hand washing facilities, in this study only $1.3 \%$ of households had hand washing places.

Trimming of finger nails at least once a week reduce fecal oral diseases (37). In our study majority of caretakers and their corresponding children had trimmed finger nails ( $83.8 \%$ and $87.2 \%$ respectively). Our findings disagree those of Sekota town, Ethiopia (38) which found majority of the children had unclean finger nails $68.3 \%$. The disparity can be due to difference in locations, our study was conducted in rural areas while that of Ethiopia was conducted in urban locations were habit of keeping finger nails is perceived to be part of beauty and being modern. 
Disposal of children faeces and conditions of child finger nails were found to be significantly associated with STH infection, thus, children that defecate in the latrine had a higher likelihood $(p=0.031)$ of getting infection compared to those defecating in potties, on the ground and nappies. This can be expected to happen in latrine that have unfinished floor and those not well cleaned. Such kinds of latrines favors the transmission of hookworms (39) in children entering toilets barefoot.

Our results show that children with untrimmed finger nails were more likely to be infected $(p=0.001)$ than those with trimmed finger nails. Our finding agree with previous studies $(6,40,41)$. Increased risk of infection for children with untrimmed finger nails is because long nails can hide contamined soil obtained by child during play. When children use their contaminated hands to eat foods, or when children bite or suck finger nails, they are likely to be exposed to STH infection $(42,43)$. Lack of association in most of the investigated factors is mainly due to small number of infected cases.

\section{Limitations}

Only single stool specimen was analyzed and might result to underestimation of STH prevalence because of variation in eggs excretion over time. The small number of STH infections made it impossible to assess associations of STH with socio-economic, water, sanitation and hygienic conditions.

\section{Conclusions And Recommendations}

PSAC are a potential reservoir of STHs infections in the study area, which coupled with the prevalent risk factors of transmission, form a potential source of continuity of transmission in the community, hence the need for a national deworming program extending to PSAC.

\section{Abbreviations}

PSAC: Preschool Aged Children, SAC:School Aged Children, STH:Soil-Transmitted Helminths, RCH:Reproductive and Child Health, WHO:World Health Organization, UNICEF:The United Nations International Children's Fund.

\section{Declarations}

\section{Acknowledgements}

The authors wish to thank Mr. Badi. H. Badi, Mr. Rajab Mnyangema, and Ms. Mary Joseph for their assistance in data collection and sample processing. Special thanks go to Ward and Village leaders and our respondents

\section{Authors' contributions}


UM designed the study and collected data, UM and DT performed statistical analysis, UM and DT wrote the manuscript. All authors read and approved the final manuscript.

\section{Availability of data and materials}

Data supporting the findings of this study are available on reasonable request from the corresponding author (UM).

\section{Ethics approval and consent to participate}

The study was conducted after obtaining ethical clearanceMuhimbili University of Allied and Health Sciences Ethical Review Board. Permission was also granted by the district, ward and village administrative authorities. Informed written consent was obtained from parents/guardians of preschool aged children.

\section{Consent for publication}

Not applicable.

\section{Competing interests}

The authors declare that they have no competing interests.

\section{References}

1. WHO. Eliminating soil transmitted helminthiases as a public health problem in children. Geneva:World Health Organisation; 2012.90pg. Report No.: WHO/HTM/NTD/PCT/2012.4.

2. WHO. Soil-transmitted helminth infections [Internet]. 2018 [cited 2019 Feb 1]. Available from:https://www.who.int/news-room/fact-sheets/detail/soil-transmitted-helminth-infections.

3. WHO. Guideline: Preventive chemotherapy to control soil-transmitted helminth infections in at-risk population groups. Geneva. World Health Organization (WHO). 2017. 75 p.

4. Horiuchi S, Uga S. Modified flotation method, an effective technique for recovering helminth eggs in soil. Parasitol Int. 2016;65(5):576-9. Available fro: http://doi:10.1016/j.parint.2016.04.010.

5. WHO. Research priorities for helminth infections. Geneva. world health organisation.2012.196p. Repot No.: 972.

6. Novianty S, Dimyati Y, Pasaribu S, Pasaribu AP. Risk factors for soil-transmitted helminthiasis in preschool children living in Farmland, North Sumatera, Indonesia. J Trop Med. 2018;2018. Available from: https://doi.org/10.1155/2018/6706413.

7. Strunz EC, Addiss DG, Stocks ME, Ogden S, Utzinger J, Freeman MC. Water, sanitation, hygiene, and soil-transmitted helminth infection: a systematic review and meta-analysis. PLoS Med. 2014;11(3). Available from: http://doi.org/10.1371/journal.pmed.1001620. 
8. WHO.Investing to overcome the global impact of neglected tropical diseases: third WHO report on neglected diseases. Geneva: World Health Organisation; 2015. 211p. Report No.: WHO/HTM/NTD/2015.1.

9. Envision. Tanzania work plan: FY 2016 project year 5: October2015-September 2016. 2016; Available at: www.ntdenvision.org.

10. Ministry of Health and Soacial Welfare (MoHSW) (Tz). Implementation guideline for vitamin A supplimentation and deworming. Dar es Salaam; (MoHSW). 2011. 64p.

11. Ministry of Health and Social Welfare (Tz). Tanzania National Nutrition Survey 2014. Dar es Salaam;Tanzania Food and Nutrition Centre; 2014. 96p.

12. Agbozo F, Colecraft E, Jahn A, Guetterman T. Understanding why child welfare clinic attendance and growth of children in the nutrition surveillance programme is below target: Lessons learnt from a mixed methods study in Ghana. BMC Nurs. 2018;17(1):1-14.

13. Clohossey PC, Katcher HI, Mogonchi GO, Nyagoha N, Isidro MC, Kikechi E, et al. Coverage of vitamin A supplementation and deworming during Malezi Bora in Kenya. J Epidemiol Glob Health. 2014;4(3):169-76.

14. Lima RB, Ferreira HS, Cavalcante AL, Santos LGML, Vieira RCS, Assunção ML. Coverage and educational actions related to the national vitamin A supplementation program: a study in children from the state of Alagoas. J Pediatr (Rio J). 2018;(xx).

15. Ministry of Health, Community Development, Gender, Elderly and Children (MoHCDGEC) [Tanzania Mainland], Ministry of Health (MoH) [Zanzibar], National Bureau of Statistics (NBS), Office of the Chief Government Statistician (OCGS), and ICF.Tanzania Demographic and Health Survey and Malaria Indicator Survey (TDHS-MIS) 2015-16. Dar es Salaam, Tanzania, and Rockville, Maryland, USA: MoHCDGEC, MoH, NBS, OCGS, and ICF; 2016. 630p.

16. Ministry of Health, Community Development, Gender, Elderly and Children (MoHCDGEC) [Tanzania Mainland], Ministry of Health (MoH) [Zanzibar], Tanzania Food and Nutrition Centre (TFNC), National Bureau of Statistics (NBS), Office of the Chief Government Statistician (OCGS) [Zanzibar] and UNICEF. Tanzania National Nutrition Survey using SMART Methodology (TNNS) 2018. Dar es Salaam, Tanzania: MoHCDGEC, MoH, TFNC, NBS, OCGS, and UNICEF; 2019. 144p.20.

17. Sousa-Figueiredo JC, Basáñez M-G, Mgeni AF, Khamis IS, Rollinson D, Stothard JR. A parasitological survey, in rural Zanzibar, of pre-school children and their mothers for urinary schistosomiasis, soiltransmitted helminthiases and malaria, with observations on the prevalence of anaemia. Ann Trop Med Parasitol. 2008;102(8):679-92.

18. National Bureau of Statistics (NBS), Office of the Chief Government Statistician (OCGS) [Zanzibar]. 2012 population and housing census. Dar es Salaam: NBS and OCGS; 2013. 264p.

19. National Bureau of Statistics (NBS). Pwani region socio- economic profile, 2013. Dar es Salaam: NBS; 2014. 210p.

20. Torell E, Mmochi A. Mkuranga Governance Baseline, Coastal Resources Centre. 2006;18. Available from: https://www.crc.uri.edu/download/Mkuranga_baseline.pdf 
21. Weldesenbet $H$, Worku A, Shumbej T. Prevalence, infection intensity and associated factors of soil transmitted helminths among primary school children in Gurage zone, South Central Ethiopia: A cross-sectional study design. BMC Res Notes. 2019;12(1).

22. Stothard JR, Imison E, French MD, Sousa-figueiredo JC, Khamis IS, Rollinson D. Soil-transmitted helminthiasis among mothers and their pre-school children on Unguja Island, Zanzibar with emphasis upon ascariasis. Parasitology. 2008 Oct 8;135(12):1447.

23. WHO. Bench aid for diagnosis of intestinal parasites.Geneva: world health organization; 1994. 23p.

24. Montresor, A, Crompton, David W. T, Hall, A, Bundy, D. A. P, Savioli, L. et al. Guidelines for the evaluation of soil-transmitted helminthiasis and schistosomiasis at community level: a guide for managers of control programmes. Geneva: World Health Organization; 1998. 34p. available from:https://apps.who.int/iris/handle/10665/63821.

25. WHO and UNICEF. Core questions on drinking-water and sanitation for household surveys. Geneva:world health organisation; 2006. 25p.

26. WHO. Helminth control in school age children: a guide for managers of control programmes. $2^{\text {nd }}$ ed. Geneva: World Health Organisation; 2011. 90p.

27. Kumar D, Kumari R, James KK, Sekharan B. Soil-transmitted helminth infections and the associated risk factors in pre-primary school children, Kiwangwa Rural Ward. Vol. 6, Bagamoyo District, Tanzania. Asian J. Med. Pharm. Res. 2016. Available from: http://science-line.com.

28. School Deworming at glance. Geneva: https://www.who.int/intestinal_worms/resources/en/at_a_glance.pdf;2003. WHO.

29. Echazú A, Bonanno D, Juarez M, Cajal SP, Heredia V, Caropresi S, et al. Effect of Poor Access to Water and Sanitation As Risk Factors for Soil-Transmitted Helminth Infection: Selectiveness by the Infective Route. Steinmann P, editor. PLoS Negl Trop Dis. 2015 Sep 30;9(9). Available from: doi:10.1371/journal.pntd.0004111.

30. Twaweza (Tz). Clean and safe?: water, sanitation and hygiene. Dar es Salaam: Twaweza. 2017. 12p. Report No.: 40.

31. Sanitation WSP, Toolkit M. Management of Child Feces: Study Design and Measurement Tips. 2015; (July).

32. Bain R, Luyendijk R. Are burial or disposal with garbage safe forms of child faeces disposal? An expert consultation. Waterlines. 2015;34(3):241-54. Available from: http://dx.doi.org/10.3362/17563488.2015.023.

33. Mwakitalima A, Massa K, Seleman A, Kassile T. Scaling up rural sanitation in Tanzania: evidence from the National Sanitation Campaign. J Water Sanit Hyg Dev. 2018;8(2):290-306. Available from:http://doi.org/10.2166/washdev.2018.072.

34. Islam M, Ercumen A, Ashraf S, Rahman M, Shoab AK, Luby SP, et al. Unsafe disposal of feces of children $<3$ years among households with latrine access in rural Bangladesh: Association with household characteristics, fly presence and child diarrhea. PLoS One. 2018;13(4):1-13. Available from: https://doi.org/10.1371/journal. pone.0195218. 
35. Seimetz E, Boyayo A, Mosler $\mathrm{H}$. The influence of contextual and psychosocial factors on handwashing. Am. J. Trop. Med. Hyg. 2016;94(6):1407-17. Available from: http://doi.org/10.4269/ajtmh.15-0657.

36. Briceño B, Yusuf A. Scaling Up Handwashing and Rural Sanitation: Findings from a Baseline Survey in Tanzania. 2012;(September):1-33. Available from: http://wsp.org/scalingupsanitation .

37. Pane R, Andayani LS. Relationship between the cleanliness of nails and the usage of footwear with the incidence of helminths infections on elementary student in Sibolga of 2019. BloEx J. 2019;4552. Available from: https://doi.org/10.33258/bioex.v2i1.107.

38. Kassaw MW, Abebe AM, Tlaye KG, Zemariam AB, Abate BB. Prevalence and risk factors of intestinal parasitic infestations among preschool children in Sekota town, Waghimra zone, Ethiopia. BMC Pediatr. 2019;19(1):1-10. Available from: https://doi.org/10.1186/s12887-019-1774-2.

39. Worrell CM, Wiegand RE, Davis SM, Odero KO, Blackstock A, Cuéllar VM, et al. A cross-sectional study of water, sanitation, and hygiene-related risk factors for soil-transmitted helminth infection in urban school- and preschool-aged children in Kibera, Nairobi. Deribe K, editor. PLoS One. 2016 Mar 7;11(3):e0150744.

40. Goel S, Tank R, Singh A, Khichi S, Goyal P, Arya R. Prevalence and risk factors of soil transmitted helminths from rural field practice area of a tertiary care center from northern India. Int J Res Med Sci. 2016;4(6):1983-7. Available from: http://dx.doi.org/10.18203/2320-6012.ijrms20161746.

41. Maru DS. Prevalence of intestinal parasitic infections and associated risk factors among school children in Adigrat town, Northern Ethiopia. Int J Emerg Trends Sci Technol. 2017;04(01):4943-8. Available from: https://dx.doi.org/10.18535/ijetst/v4i1.03.

42. Adewale B, Adedeji A, Folorunsho S, Demehin P, Akinsanya B. Soil-transmitted helminth infections and risk factors among primary school pupils in Lagos, Nigeria. BMJ Glob Heal. 2017;2(Suppl 2):A61.3-A62.Available from: http://dx.doi.org/10.1136/bmjgh-2016-000260.165

43. Oyebamiji DA, Ebisike AN, Egede JO, Hassan AA. Knowledge, attitude and practice with respect to soil contamination by soil-transmitted helminths in Ibadan, Southwestern Nigeria. Parasite Epidemiol Control. 2018;3(4). Available from: https://doi.org/10.1016/j.parepi.2018.e00075.

\section{Tables}

\section{Table 1: Socio-demographic characteristics of the study population $(\mathrm{N}=525)$}




\begin{tabular}{|c|c|c|}
\hline Variable studied & Frequency & Percent \\
\hline \multicolumn{3}{|l|}{ Child sex; } \\
\hline Male & 250 & 47.6 \\
\hline Female & 275 & 52.4 \\
\hline \multicolumn{3}{|c|}{ Age groups of PSAC (months); } \\
\hline $12-23$ & 122 & 23.2 \\
\hline $24-35$ & 117 & 22.3 \\
\hline $36-47$ & 126 & 24.0 \\
\hline $48-60$ & 160 & 30.5 \\
\hline \multicolumn{3}{|c|}{ Age groups of caretaker (years) } \\
\hline$\leq 19$ & 36 & 6.9 \\
\hline $20-29$ & 233 & 44.4 \\
\hline $30-39$ & 168 & 32.0 \\
\hline $40-49$ & 66 & 12.6 \\
\hline$\geq 50$ & 22 & 4.2 \\
\hline \multicolumn{3}{|l|}{ Education level of caretaker } \\
\hline Never attended school & 103 & 19.6 \\
\hline Primary education & 332 & 63.2 \\
\hline Secondary education & 68 & 12.8 \\
\hline Tertiary education & 23 & 4.4 \\
\hline \multicolumn{3}{|l|}{ Marital status of caretaker } \\
\hline Never Married & 60 & 11.4 \\
\hline married/living together & 425 & 81.0 \\
\hline widow/divorced & 40 & 7.6 \\
\hline \multicolumn{3}{|l|}{ Occupation of caretaker } \\
\hline Public/ Private employee & 29 & 5.5 \\
\hline Self employee & 158 & 30.1 \\
\hline Peasant & 96 & 18.3 \\
\hline House wife & 242 & 46.1 \\
\hline
\end{tabular}


Table 2: Hand washing and nail trimming habit of the caretakers and or children $(\mathrm{N}=525)$

\begin{tabular}{|c|c|c|}
\hline Variable studied & Frequency & Percent \\
\hline \multicolumn{3}{|c|}{ Hand wash habit Before preparing food } \\
\hline Use water and soap & $67(12.8)$ & 12.8 \\
\hline Water only & $415(79.0)$ & 79.0 \\
\hline Don't wash usually & $43(8.2)$ & 8.2 \\
\hline \multicolumn{3}{|c|}{ Hand wash habit Before eating and feeding a child } \\
\hline Use water and soap & $68(13.0)$ & 13.0 \\
\hline Water only & $457(87.0)$ & 87.0 \\
\hline Don't wash usually & 0 & 0 \\
\hline \multicolumn{3}{|c|}{ Hand wash habit After toilet use } \\
\hline Water and soap & 179(34.1) & 34.1 \\
\hline Water only & $346(65.9)$ & 65.9 \\
\hline Don't wash usually & 0 & 0 \\
\hline \multicolumn{3}{|c|}{ Hand wash habit After cleaning a defecated child } \\
\hline Water and soap & $121(23.0)$ & 23.0 \\
\hline Water only & 404(77.0) & 77.0 \\
\hline Don't wash usually & 0 & 0 \\
\hline \multicolumn{3}{|l|}{ Caretakers finger nails } \\
\hline Untrimmed & 85 & 16.2 \\
\hline Trimmed & 440 & 83.8 \\
\hline \multicolumn{3}{|l|}{ Child finger nails } \\
\hline Untrimmed & 67 & 12.8 \\
\hline Trimmed & 488 & 87.2 \\
\hline
\end{tabular}

Table 3: Influence of water, sanitation and hygiene condition on STH 


\begin{tabular}{|c|c|c|c|}
\hline Variable studied & $\begin{array}{l}\text { Infected } \\
(\%)\end{array}$ & $\begin{array}{l}\text { Not infected } \\
(\%)\end{array}$ & $\begin{array}{l}P \\
\text { value }\end{array}$ \\
\hline \multicolumn{4}{|c|}{$\begin{array}{l}\text { Quality of the source used to obtain drinking water } \\
(\mathrm{N}=525)\end{array}$} \\
\hline Improved & $7(1.4)$ & 490(98.6) & 1.000 \\
\hline Unimproved & $0(0.0)$ & $28(100.0)$ & \\
\hline \multicolumn{4}{|c|}{ Treatment of drinking water $(\mathrm{N}=525)$} \\
\hline Yes & $0(0.0)$ & $28(100.0)$ & 1.000 \\
\hline No & $7(1.4)$ & 490(98.6) & \\
\hline \multicolumn{4}{|c|}{ Availability of latrine $(\mathrm{N}=525)$} \\
\hline Latrine Present & $7(1.4)$ & $504(98.6)$ & \\
\hline Latrine Not present & $0(0.0)$ & 14(100.0) & 1.000 \\
\hline \multicolumn{4}{|c|}{ Quality of latrine $(\mathrm{N}=511)$} \\
\hline Improved non shared & $3(1.3)$ & 220(98.7) & \\
\hline Other wise & $4(1.4)$ & 284(98.6) & 1.000 \\
\hline \multicolumn{4}{|c|}{ Latrine utilization $(\mathrm{N}=511)$} \\
\hline Proper & $4(1.0)$ & 401(99.0) & \\
\hline Not proper & $3(2.8)$ & 103(97.2) & 0.160 \\
\hline \multicolumn{4}{|c|}{ Place where child defacate $(\mathrm{N}=525)$} \\
\hline Latrine & $3(1.2)$ & 242(98.8) & \\
\hline Pot & $2(1.5)$ & 134(98.5) & \\
\hline On ground & $1(0.7)$ & 141(99.3) & 0.031 \\
\hline Nappy & $1(50.0)$ & $1(50.0)$ & \\
\hline \multicolumn{4}{|c|}{ Means of disposing child faeces $(\mathrm{N}=280)$} \\
\hline Rinse/put into latrine & $4(1.5)$ & 256(98.5) & \\
\hline Burry in the soil & $0(0.0)$ & $20(100.0)$ & 1.000 \\
\hline \multicolumn{4}{|c|}{ Hand washing habit after defecation $(\mathrm{N}=525)$} \\
\hline Water and soap & $1(0.6)$ & 178(99.4) & 0.432 \\
\hline Water only & $6(1.7)$ & $340(98.3)$ & \\
\hline
\end{tabular}




\begin{tabular}{|lccc|}
\hline Water and soap & $0(0.0)$ & $121(100)$ & 0.361 \\
\hline Water only & $7(1.7)$ & $397(98.3)$ & \\
\hline Child finger nail $(\mathrm{N}=525)$ & & & \\
\hline Trimmed & $2(0.4)$ & $456(99.6)$ & 0.001 \\
\hline Untrimmed & $5(7.5)$ & $64(92.5)$ & \\
\hline Caretakers finger nail $(\mathrm{N}=525)$ & & & 1.000 \\
\hline Trimmed & $6(1.4)$ & $434(98.6)$ & \\
\hline Untrimmed & $1(1.2)$ & $84(98.8)$ & \\
\hline
\end{tabular}

\section{Figures}

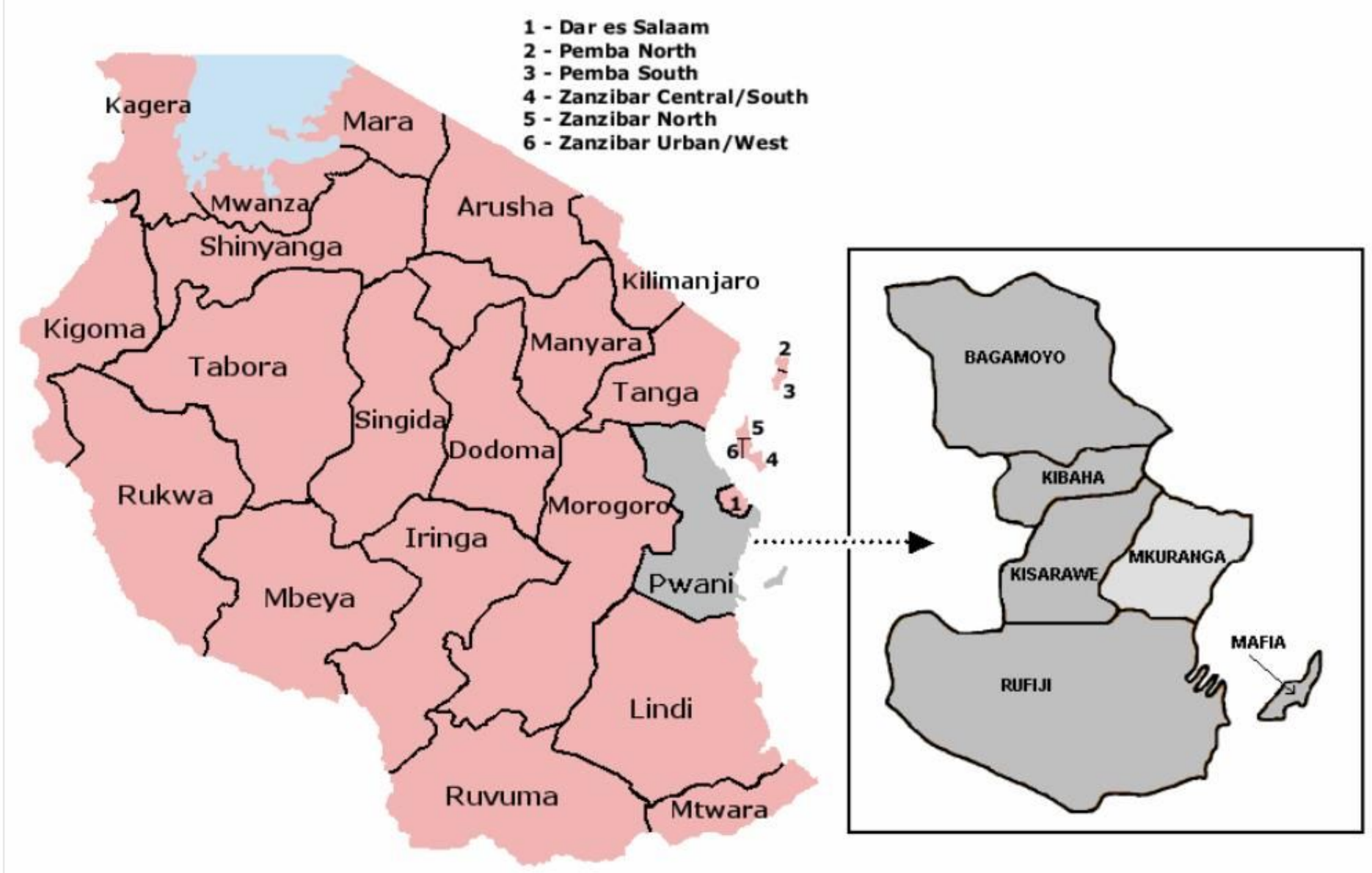

Figure 1

Map of Tanzania showing the location of Mkuranga district (20). 


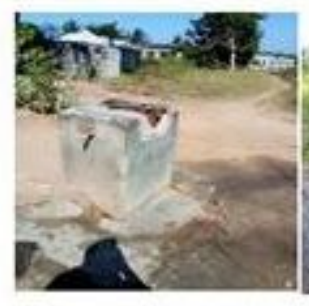

(a)

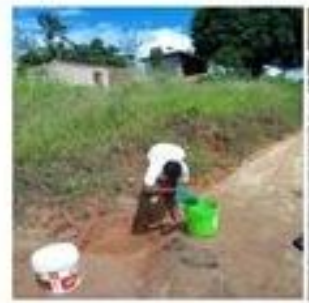

(d)

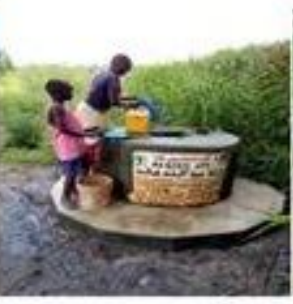

(b)

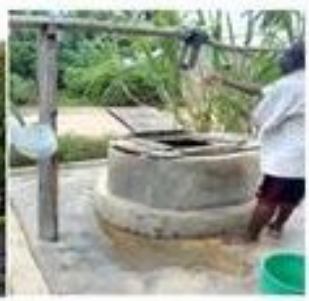

(c)

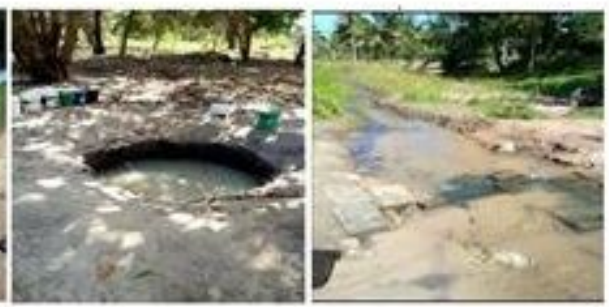

(c)

(f)

Figure 2: Images of different types of water sources available in the study area: (a) Tap water, (b) Protected well, (c) Tube well/borehole, (d) Unprotected spring (e) Unprotected well (f) River (photos by first author).

\section{Figure 2}

Images of different types of water sources available in the study area: (a) Tap water, (b) Protected well, (c) Tube well/borehole, (d) Unprotected spring (e) Unprotected well (f) River (photos by first author).
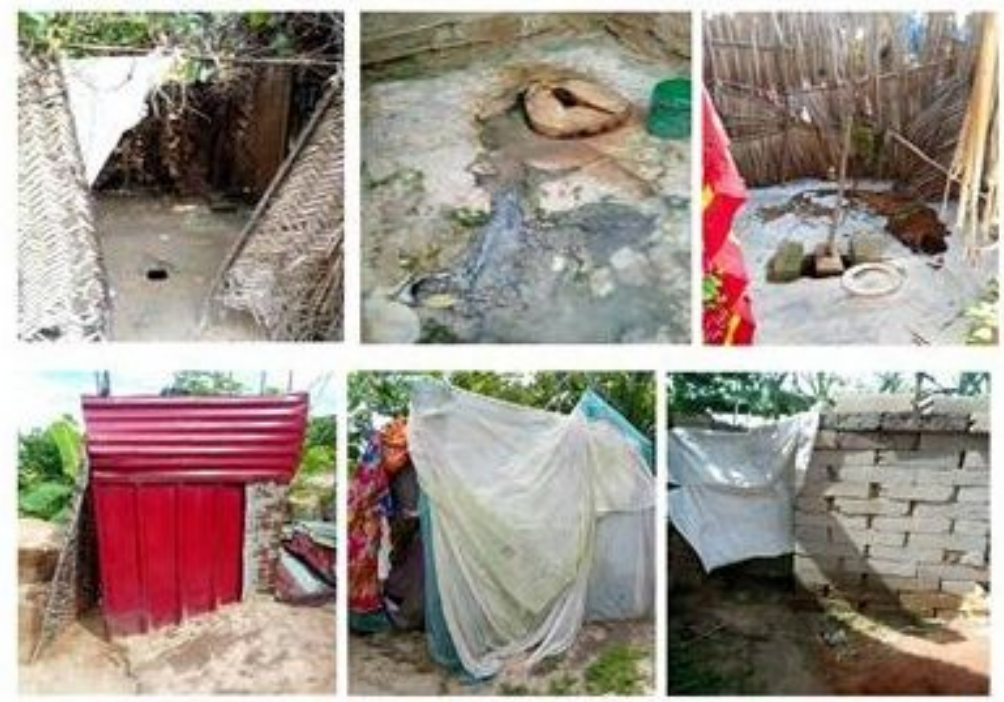

Figure 3: Images showing conditions of some latrines found in the study areas: top pictures shows latrine with poor floor and bottom pictures show latrine which do not provide privacy (photos by first author).

\section{Figure 3}

Images showing conditions of some latrines found in the study areas: top pictures shows latrine with poor floor and bottom pictures show latrine which do not provide privacy (photos by first author). 


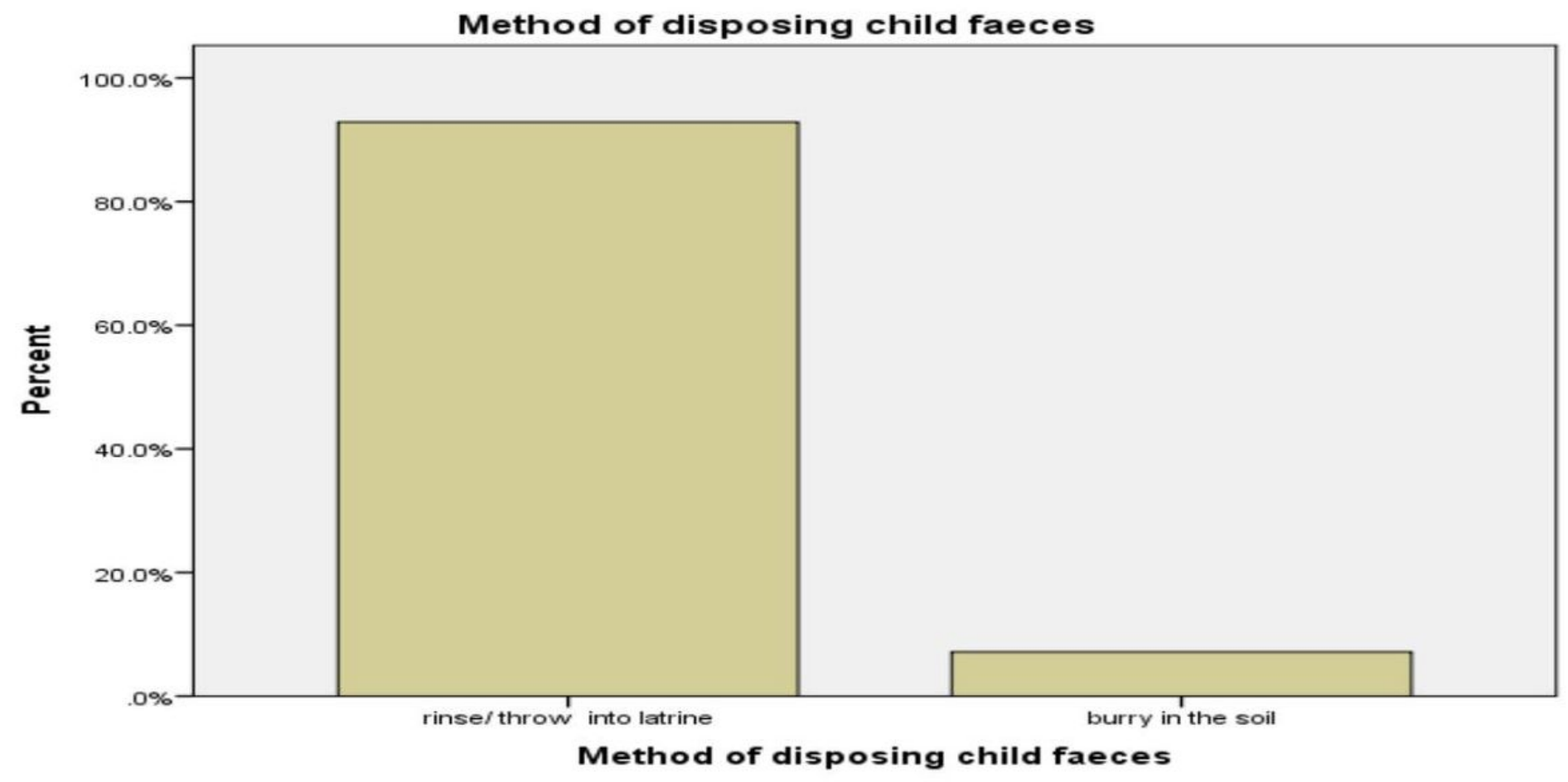

Figure 4

methods used by caretakers to dispose children faeces. 